\title{
Metabolic Effects and Pharmacokinetics of Intravenously Administered Dichloroacetate in Humans
}

\author{
P. G. Wells, G. W. Moore, D. Rabin, G. R. Wilkinson, J. A. Oates, and P. W. Stacpoole \\ Divisions of Clinical Pharmacology and Endocrinology, Departments of Pharmacology and Medicine, \\ Vanderbilt University School of Medicine, Nashville, Tennessee, USA
}

Summary. Dichloroacetate decreases plasma glucose, lactate, and alanine concentrations in normal and diabetic subjects, and lowers lactate concentrations and increases survival in animals with experimentally induced lactic acidosis. The relationship between these effects and plasma dichloroacetate concentrations have not been previously studied in man. Dichloroacetate $(1-50 \mathrm{mg} / \mathrm{kg}$ ) was infused over 30 min to 16 healthy subjects and plasma drug concentrations were followed by gas chromatography over the next $8 \mathrm{~h}$. Peak plasma concentrations were linearly related to the dose $(r=0.98, p<0.001)$ up to $30 \mathrm{mg} / \mathrm{kg}$, above which 4 of 7 subjects had disproportionately high plasma drug concentrations. Nonlinear disposition was also indicated by the convex decreasing plasma elimination curves; levels declining less rapidly initially than later. At plasma concentrations below $10 \mu \mathrm{g} / \mathrm{ml}$, elimination was monoexponential with a half-life of $32 \pm 11$ min (mean $\pm \mathrm{SD}$ ). Plasma drug clearance also decreased with doses greater than $20 \mathrm{mg} / \mathrm{kg}$. Within $2 \mathrm{~h}$ of administration of the maximally effective dichloroacetate dose of $35 \mathrm{mg} / \mathrm{kg}$, plasma lactate concentrations fell $75 \%$ below baseline and alanine fell $50 \%$ below baseline, while blood glucose was unaffected.

Key words: Dichloroacetate, pharmacokinetics, lactate, lactic acidosis, alanine, glucose.

Over the past several years, the effects of dichloroacetate (DCA) on intermediary metabolism have been studied extensively in several experimental models. DCA reduces blood glucose concentrations in both diabetic and fasted animals but not in healthy, fed animals [1-4]. The probable mechanism is through activation of pyruvate dehydrogenase via direct inhibition of pyruvate dehydrogenase kinase $[5,6]$. Because lactate and alanine exist in equilibrium with pyruvate, their metabolic fates are also influenced by pyruvate oxidation. By stimulating pyruvate dehydrogenase activity, DCA accelerates pyruvate, lactate and alanine oxidation. Consequently, release of lactate and alanine from peripheral tissues into the circulation is reduced [7], and fewer three-carbon precursors are available for hepatic glucose synthesis.

We recently reported that orally administered sodium DCA, at a daily dose of approximately $50 \mathrm{mg} / \mathrm{kg}$, rapidly and significantly decreased plasma lactate and alanine concentrations in maturity-onset diabetic patients who had normal or slightly elevated basal plasma lactate concentrations [8]. Other workers have shown that intravenously administered DCA can prevent or even reverse hyperlactatemia and lactic acidosis induced in animals by phenformin administration [9-13], acute hepatitis [14], functional hepatectomy $[15,16]$, epinephrine infusion $[12,17]$, exercise $[18,19]$ or hypoxia [12].

These findings suggested that DCA may be useful in the treatment of lactic acidosis in humans, where the mortality with current therapy exceeds $50 \%$ [20]. Accordingly, the present study was designed to evaluate in healthy volunteers the effects of intravenously administered DCA on plasma concentration of lactate, alanine and glucose and their relationship to the pharmacokinetics of DCA.

\section{Materials and Methods}

Sixteen healthy subjects ( 15 male, 1 femaie), 25 to 45 years old (mean 30 years), and within $10 \%$ of ideal body weight, were studied. They were taking no drugs, and their health was normal on physical examination, complete blood count and routine biochemical tests of hepatic and renal function. The protocol was 

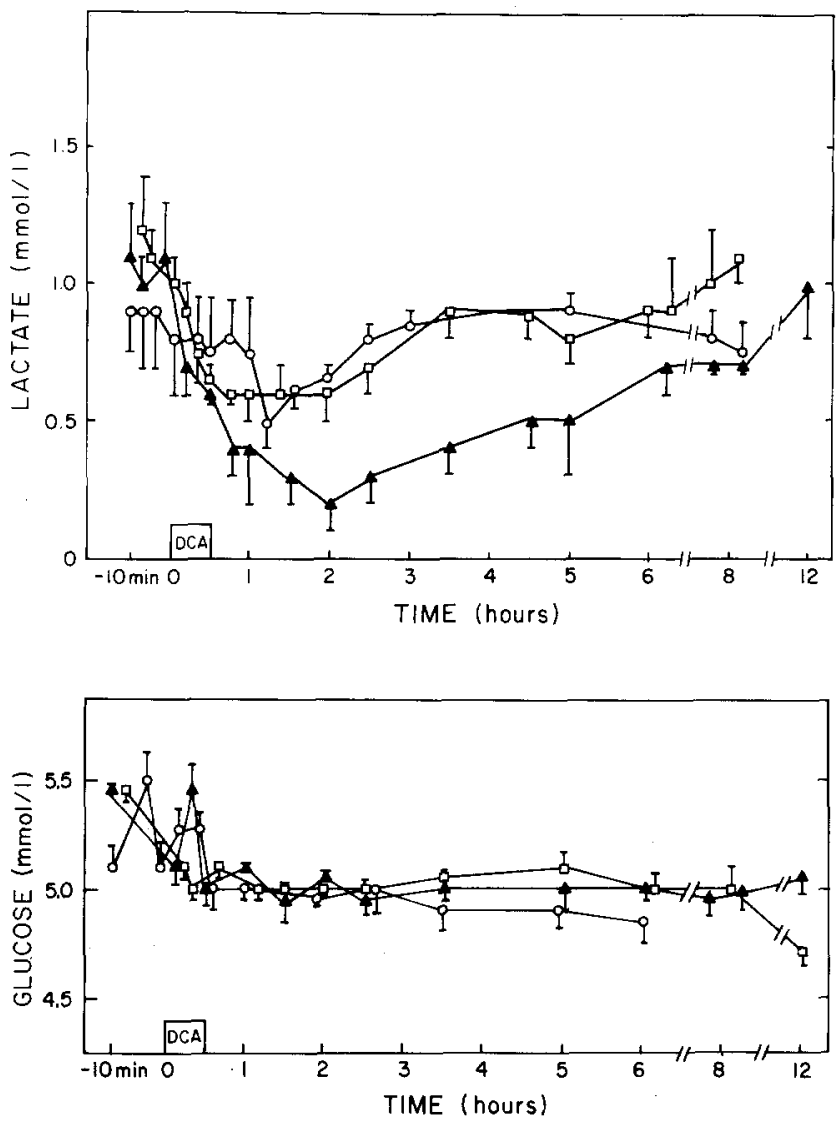

approved and monitored by the Vanderbilt University Committee for the Protection of Human Subjects. Informed written consent was obtained from each person before the study.

DCA was supplied in $10 \mathrm{ml}$ ampules as the sodium salt, $100 \mathrm{mg} /$ $\mathrm{ml}$, in phosphate buffer, pH 7 (Ciba-Geigy Corp., Summit, NJ). On the morning following an overnight fast, DCA was diluted in 130 to $200 \mathrm{ml}$ normal saline and infused at a constant rate by a Harvard infusion pump into a superficial forearm vein for $30 \mathrm{~min}$. Doses of $1,5,10,15,20,25,30,35$ and $50 \mathrm{mg} / \mathrm{kg}$ body weight were administered in increasing strength, each subject being studied once at a single dose. Blood samples were drawn from a superficial vein in the other arm at 30 or 60 min intervals over a $12 \mathrm{~h}$ period. Blood pressure, pulse and electrocardiogram (ECG) were monitored intermittently, and subjects remained fasting and supine throughout the study.

Blood samples were centrifuged at $4{ }^{\circ} \mathrm{C}$, and plasma was separated for analysis of $\mathrm{pH}$ and glucose [21], lactate [22], alanine [23], bicarbonate, and DCA [24] concentrations. For determination of plasma DCA $50 \mu 1$ of internal standard in aqueous solution (trichloroacetic acid, $100 \mu \mathrm{g} / \mathrm{ml}$; J. T. Baker Chemical Company, Phillipsburg, NJ) was added to $1 \mathrm{ml}$ plasma followed by $2 \mathrm{ml} 14 \%$ $(w / v)$ boron trifluoride-butanol (Analabs, North Haven, CT) in Viton ${ }^{\circledR}$-sealed $6 \mathrm{ml}$ vials (Pierce Chemical Company, Rockford, IL). The vial was placed in a water bath $\left(100^{\circ} \mathrm{C}\right)$ for $10 \mathrm{~min}$, cooled to room temperature and then distilled water $(1 \mathrm{ml})$ and benzene $(2 \mathrm{ml})$ were added. After shaking for $5 \mathrm{~min}$, the benzene layer was separated by centrifugation and a $1 \mu$ l aliquot injected into a 2100 series gas chromatograph (Varian, Walnut Creek, CA) equipped with a tritiated titanium electron capture detector. The glass column was $1.83 \mathrm{~m} \times 2 \mathrm{~mm}$, packed with $100 / 120$ mesh Chromosorb

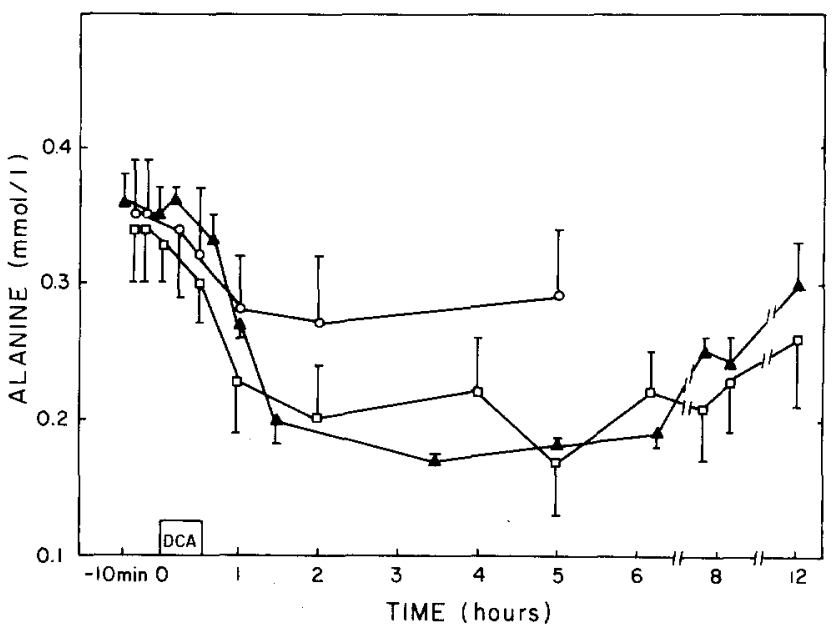

Fig. 1. Effect of intravenously administered DCA on mean ( \pm SEM) plasma lactate, alanine and glucose concentrations in fasted, healthy, human subjects. DCA $(15-50 \mathrm{mg} / \mathrm{kg})$ was infused over $30 \mathrm{~min}$. Metabolite plasma concentrations are shown following DCA doses of $15-30 \mathrm{mg} / \mathrm{kg}$ (open circles, $\mathrm{n}=5$ ), $35 \mathrm{mg} / \mathrm{kg}$ (solid triangles, $\mathrm{n}=3$ ) and $50 \mathrm{mg} / \mathrm{kg}$ (open squares, $\mathrm{n}=6$ )

101 (Analabs), and the nitrogen flow rate was $30 \mathrm{ml} / \mathrm{min}$. Operating temperatures were: injector, $250^{\circ} \mathrm{C}$; oven, $180^{\circ} \mathrm{C}$; detector $260^{\circ} \mathrm{C}$. The concentration of DCA was obtained from daily linear calibration curves of the DCA/internal standard peak height ratios obtained after the addition of known amounts of DCA. Urinary recovery of DCA over $12 \mathrm{~h}$ was measured in three subjects.

In vitro plasma binding of $\left[1,2-{ }^{14} \mathrm{C}\right]$ DCA $(>99 \%$ pure, New England Nuclear, Boston, MA) was estimated for one subject by equilibrium dialysis against phosphate buffer $\mathrm{pH} 7.4$, using semimicrocells at $37^{\circ} \mathrm{C}$ as previously described [25].

The half-life was calculated by linear regression from the loglinear portion of the plasma disappearance curve, and plasma clearance was estimated by dividing the dose of DCA administered intravenously by the total area under the plasma concentrationtime curve using the trapezoidal rule with extrapolation to infinity.

Termination of the study because of emergent toxicologic information precluded full statistical analysis of the data as insufficient subjects had been studied at each dose level.

\section{Results}

\section{Metabolic Effects}

Figure 1 shows the time course of changes in lactate, alanine and glucose following administration of DCA $15-50 \mathrm{mg} / \mathrm{kg}$. At concentrations of 1 and $10 \mathrm{mg} / \mathrm{kg}$ 
(data not shown), DCA had no effect on these indices. The results obtained from infusions of $15-30 \mathrm{mg} /$ $\mathrm{kg}$ were combined and expressed as the mean \pm SEM because of the close similarity in metabolic responses achieved throughout this dose range. While there was intersubject variability of four- and two-fold among basal plasma lactate and alanine concentrations, respectively, this was not reflected in any consistent trend with respect to the response to DCA.

Maximal lactate depression for DCA doses between 15 and $50 \mathrm{mg} / \mathrm{kg}$ occurred $1-2 \mathrm{~h}$ after beginning drug infusion. Lactate concentrations remained below control values for $8-10 \mathrm{~h}$, but returned to baseline within $12 \mathrm{~h}$. At a maximally effective DCA dose of $35 \mathrm{mg} / \mathrm{kg}$ in 3 subjects, plasma lactate concentrations fell $75 \%$ below basal concentrations within $2 \mathrm{~h}$. This effect was greater than that achieved with the $50 \mathrm{mg} / \mathrm{kg}$ dose in 6 subjects. Plasma alanine concentrations decreased $50 \%$ by $1 \mathrm{~h}$, remained maximally depressed for $6 \mathrm{~h}$, and were still below baseline at $12 \mathrm{~h}$ with both $35 \mathrm{mg} / \mathrm{kg}(\mathrm{n}=3)$ and $50 \mathrm{mg} / \mathrm{kg}(\mathrm{n}=6)$ of DCA. Decreases in plasma lactate and alanine correlated linearly $(r=0.93, p<$ 0.01 ) with DCA dose and peak plasma concentration from a DCA dose of $20 \mathrm{mg} / \mathrm{kg}$ up to the maximally effective $35 \mathrm{mg} / \mathrm{kg}$ dose, despite the small number of subjects $(\mathrm{n}=8)$. Plasma glucose concentration fell only slightly, as shown by a maximal $13 \%$ decrease by $12 \mathrm{~h}$ in 6 subjects at the $50 \mathrm{mg} / \mathrm{kg}$ DCA dose.

Plasma bicarbonate concentration and venous $\mathrm{pH}$ did not change at any DCA dose. Similarly, blood pressure, pulse and ECG remained stable throughout the study. Subjective responses were confined to one subject who complained of drowsiness persisting $24 \mathrm{~h}$ following a dose of $50 \mathrm{mg} / \mathrm{kg}$.

\section{Pharmacokinetics}

Peak plasma DCA concentrations always occurred at the end of the $30 \mathrm{~min}$ infusion. Figure 2 shows that the peak plasma DCA concentration was apparently linearly related to the DCA dose, up to a dose of $30 \mathrm{mg} / \mathrm{kg}(\mathrm{r}=0.98, \mathrm{p}<0.001)$. At doses of 35 and $50 \mathrm{mg} / \mathrm{kg}$, however, 4 of 7 subjects exhibited peak plasma drug concentrations disproportionately higher than predicted by the linear relation seen at lower doses. Nonlinear disposition was also indicated by the time course of plasma DCA concentrations following drug administration (Fig. 3). The plasma DCA concentration fell in a convex decreasing fashion with respect to time, elimination becoming more rapid as plasma DCA concentrations fell to about $10 \mu \mathrm{g} / \mathrm{ml}$, below which elimination became monoexponential. This biphasic elimination was seen in all

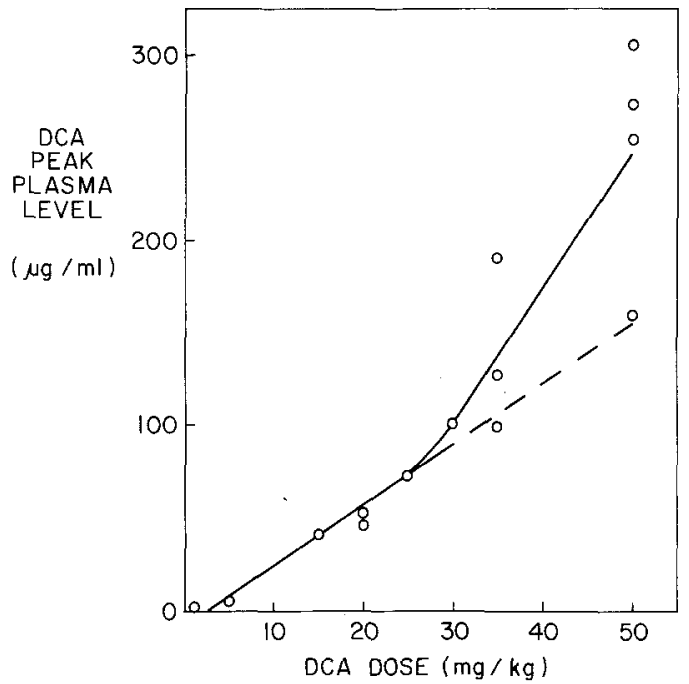

Fig. 2. Relationship between peak DCA plasma concentration ( $\mu \mathrm{g} /$ $\mathrm{ml})$ and DCA dose $(\mathrm{mg} / \mathrm{kg})$ in 14 fasted, healthy, human subjects. DCA $(1-50 \mathrm{mg} / \mathrm{kg}$ ) was infused over $30 \mathrm{~min}$

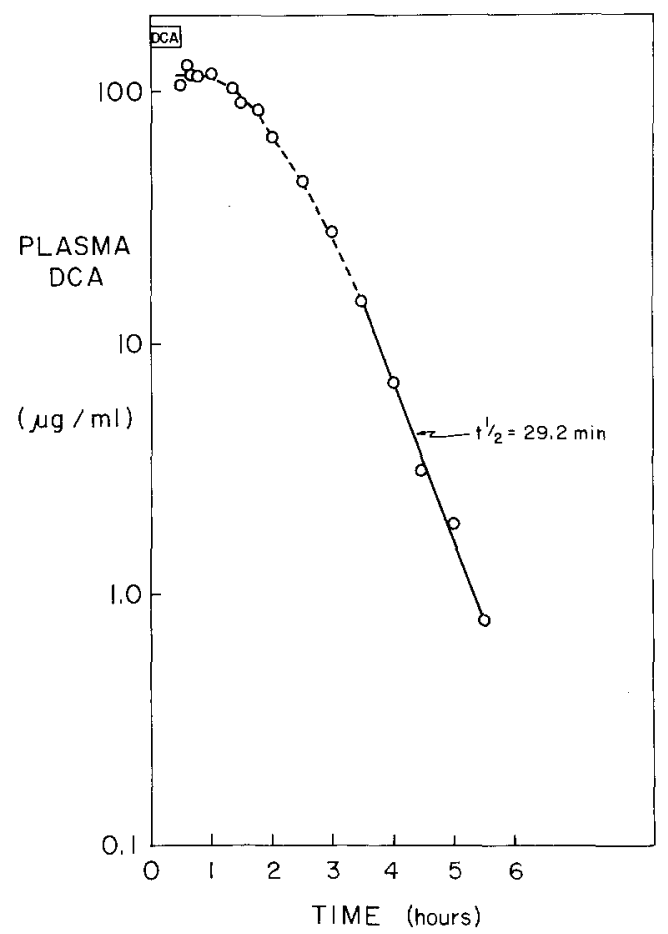

Fig. 3. Nonlinear time-course of DCA plasma elimination exemplified by data from one subject receiving $35 \mathrm{mg} / \mathrm{kg}$ of DCA over $30 \mathrm{~min}$

but one subject at all doses. The plasma clearance of DCA ranged from 0.57 to $0.081 / \mathrm{kg} / \mathrm{h}$, with an overall trend to decrease as the dose was increased above $20 \mathrm{mg} / \mathrm{kg}$ (Table 1). The mean ( \pm SD) half-life of the monoexponential phase was $32( \pm 11)$ min with a 
Table 1. Half-life and clearance of DCA following a $30 \mathrm{~min}$ infusion of $15-50 \mathrm{mg} / \mathrm{kg}$

\begin{tabular}{llll}
\hline Subject & $\begin{array}{l}\text { Dose of DCA } \\
(\mathrm{mg} / \mathrm{kg})\end{array}$ & $\begin{array}{l}\text { Half-life }^{\mathrm{a}} \\
(\mathrm{min})\end{array}$ & $\begin{array}{l}\text { Clearance } \\
(1 / \mathrm{kg} / \mathrm{h})\end{array}$ \\
\hline 1 & 15 & 16.4 & 0.33 \\
2 & 20 & 22.4 & 0.57 \\
3 & 20 & 22.7 & 0.54 \\
4 & 25 & 38.1 & 0.20 \\
5 & 30 & 29.9 & 0.14 \\
6 & 35 & 29.2 & 0.12 \\
7 & 35 & 41.7 & 0.15 \\
8 & 35 & 50.3 & 0.08 \\
9 & 50 & 23.2 & 0.10 \\
10 & 50 & 29.7 & 0.20 \\
11 & 50 & 46.4 & 0.11 \\
\hline Mean ( & $5 \mathrm{SD})$ & \multicolumn{3}{l}{} \\
\hline
\end{tabular}

${ }^{a}$ Calculated from plasma concentrations below $10 \mu \mathrm{g} / \mathrm{ml}$, as described in the methods section

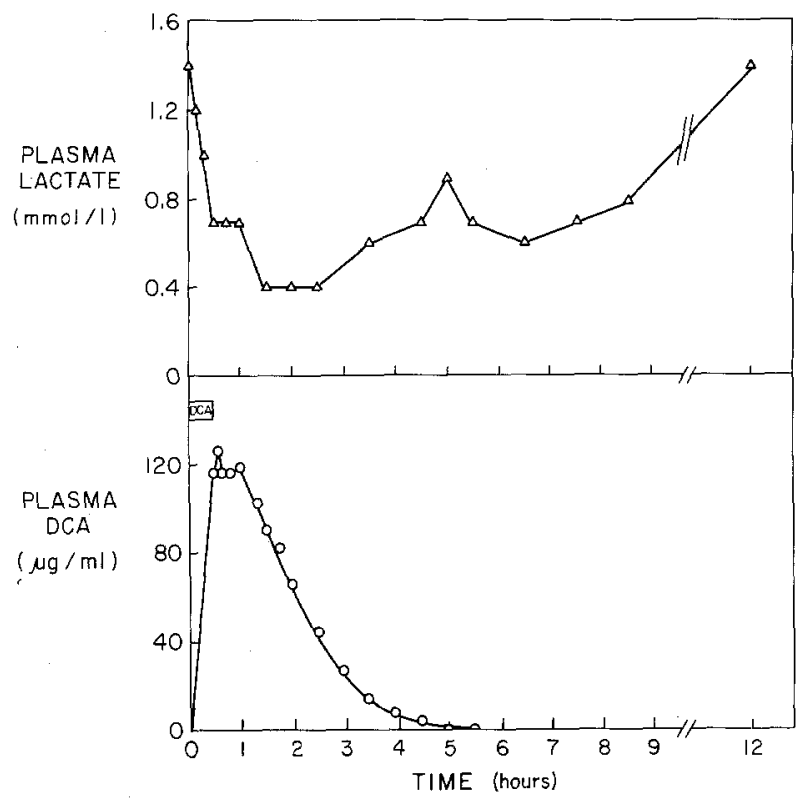

Fig. 4. Time-course relationship between plasma lactate concentration (upper panel) and DCA concentration (lower panel) exemplified by data from one subject receiving $35 \mathrm{mg} / \mathrm{kg}$ of DCA over $30 \mathrm{~min}$

range of 16 to $50 \mathrm{~min}$ (Table 1 ). Urinary recovery of DCA over $12 \mathrm{~h}$ was less than $1 \%$ of the administered dose in 3 patients. The percent of DCA bound to plasma proteins in vitro for one subject decreased from $51 \%$ to $29 \%$ over the clinical plasma concentration range of 12.5 to $300 \mu \mathrm{g} / \mathrm{ml}$, respectively.

The time course of plasma lactate depression in relation to the plasma DCA concentration is shown in Figure 4. DCA elimination from plasma was complete in $5 \mathrm{~h}$, while lactate was depressed at least $9 \mathrm{~h}$.

\section{Discussion}

These studies demonstrate that intravenously administered DCA rapidly reduces plasma lactate and alanine concentrations in humans (Fig. 1). The maximal depression of lactate and alanine occured at a DCA dose of $35 \mathrm{mg} / \mathrm{kg}$, equivalent to a plasma drug concentration of $130 \mu \mathrm{g} / \mathrm{ml}$. Despite a marked decrease in alanine and lactate concentrations, glucose concentrations remained fairly stable over the $12 \mathrm{~h}$ study period. This stability may have been due to glycogen mobilization which compensated for the effects of fasting and the blood glucose-lowering action of DCA.

There are differences in the effects of orally versus intravenously administered DCA on plasma lactate and alanine. In diabetic patients receiving $50 \mathrm{mg} /$ $\mathrm{kg}$ of DCA orally for seven days, depression of plasma lactate and alanine persisted several days beyond cessation of DCA treatment (8). In contrast, the lactate and alanine concentrations after intravenously administered DCA had returned to or toward basal levels within $12 \mathrm{~h}$ of drug administration. The reason for this discrepancy in response between chronic oral dosing and single dose intravenous drug administration is unknown, although even in the intravenous studies, lactate and alanine concentrations remained depressed up to $8 \mathrm{~h}$ after elimination of DCA from the plasma.

Peak plasma DCA concentrations increased disproportionately when DCA was infused for $30 \mathrm{~min}$ at doses above $30 \mathrm{mg} / \mathrm{kg}$ (Fig. 2), and plasma clearance of DCA decreased with doses greater than $20 \mathrm{mg} / \mathrm{kg}$ (Table 1). In addition, a slower rate of DCA elimination from the plasma compartment was observed when plasma drug concentrations exceeded $10 \mu \mathrm{g} / \mathrm{ml}$. A number of potential mechanisms, including saturable metabolism and plasma binding may be invoked to explain this nonlinear elimination, but the presently available data are insufficient to identify any specific process involved.

In light of the nonlinear pharmacokinetics, increasing doses or multiple dosing conditions would be expected to produce disproportionately high plasma DCA levels, as occurs with other drugs, such as phenytoin [26] and salicylate [27]. This phenomenon of DCA metabolism is particularly important in view of recent evidence of drug-related chronic toxicity in animals $[28,29]$, and a report of polyneuropathy developing after 4 months of daily DCA therapy in one human subject [30]. Knowledge of these toxicologic data, led to the premature termination of this study. Quantitative or qualitative interspecies variability in metabolic pathways of DCA and similar intersubject variability in humans may have 
considerable toxicologic significance, and deserve further investigation. One subject in this study complained of drowsiness up to $24 \mathrm{~h}$ after DCA administration. He was found to have a high peak DCA plasma concentration $(273 \mu \mathrm{g} / \mathrm{ml})$, which had only begun to decline by the end of the sampling period. Thus, the prolonged, high plasma concentrations, together with an increased free fraction at higher drug levels, may have been responsible for the drowsiness observed in this and other [8] individuals. The relevance of the toxicologic data from chronic, oral DCA administration with respect to the acute intravenous use of DCA in life-threatening lactic acidosis awaits further study. It is possible that less toxic analogues of DCA may provide a better therapeutic index.

Acknowledgements. We thank Dr. William W. Lacy for plasma alanine determinations and Mrs. Carolyn Sielbeck and Mrs. Sandra Goldstein for secretarial assistance.

This study was supported in part by a grant from the CibaGeigy Corp., Summit, NJ, and by research grants GM 15431, T32 AM 07061, 5M01 RR00095, and AM 20593 from the National Institutes of Health.

\section{References}

1. Lorini M, Ciman M (1962) Hypoglycaemic action of diisopropylammonium salts in experimental diabetes. Biochem Pharmacol 11: 823-827

2. Stacpoole PW, Felts JM: Diisopropylammonium dichloroacetate (DIPA) and sodium dichloroacetate (DCA) (1970) effect on glucose and fat metabolism in normal and diabetic tissue. Metabolism 19: 71-78

3. Eichner HL, Stacpoole PW, Forsham PH (1974) Treatment of streptozotocin diabetes with diisopropylammonium dichloroacetate (DIPA). Diabetes 23: 179-182

4. Blackshear PJ, Holloway PAH, Alberti KGMM (1974) The metabolic effects of sodium dichloroacetate in the starved rat. Biochem J 142: 279-286

5. Whitehouse S, Randle PJ (1973) Activation of pyruvate dehydrogenase in perfused rat heart by dichloroacetate. Biochem J 134: 651-653

6. Whitehouse S, Cooper RH, Randle PJ (1974) Mechanism of activation of pyruvate dehydrogenase by dichloroacetate and other halogenated carboxylic acids. Biochem J 141: 761-764

7. Goodman MN, Ruderman NB, Aoki TT (1978) Glucose and amino acid metabolism in perfused skeletal muscle. Diabetes 27: 1065-1074

8. Stacpoole PW, Moore GW, Kornhauser DM (1978) Metabolic effects of dichloroacetate in patients with diabetes mellitus and hyperlipoproteinemia. N Engl J Med 298: 526-530

9. Holloway PAH, Alberti KGMM (1975) Reversal of phenformin-induced hyperlactaemia by dichloroacetate in normal and diabetic rats. Diabetologia 11: 250-251

10. Holloway PAH, Alberti KGMM (1976) Phenformin-induced lactic acidosis: prevention by dichloroacetate. Clin Sci Mol Med 50: 33

11. Loubatieres A, Ribes G, Valette G (1977) Reduction par le dichloroacetate de sodium et par l'insuline des hyperlactatémies graves consécutives chez le chien anèsthesie on éveillé à l'administration de phenformine. CR Acad Sci [D] (Paris) 284: 325-327
12. Loubatieres A, Valette G, Ribes G, Loubatieres-Mariani MM, Rondot AM (1978) Dichloroacetate de sodium; son application à la thérapeutique des hyperlactatémies éxperimentales. Diabete Metab 4: 5-11

13. Arieff AI, Leach W, Lazarowitz V (1978) Treatment of experimental lactic acidosis with dichloroacetate (DCA). Clin Res 26: $410 \mathrm{~A}$

14. Johnson GAH, Alberti KGMM (1977) The metabolic effects of sodium dichloroacetate in experimental hepatitis in the rat. Biochem Soc Trans 5: 1387-1388

15. Park R, Leach W, Arieff A (1979) Dichloracetate (DCA) prevents hyperlactatemia following functional hepatectomy (HPX). Clin Res 27: 48A

16. Park R, Leach W, Arieff A (1979) Dichloroacetate (DCA) decreases extrahepatic lactate production in diabetic dogs. Clin Res 27: 374A

17. Loubatieres AL, Ribes G, Valette G (1976) Pharmacological agents and acute experimental hyperlactataemia in the dog. $\mathrm{Br}$ J Pharmacol 58: 429P

18. Zambraski EJ, Merill GF (1979) Dichloroacetate sodium (DCA) decreases plasma lactic acid (LA) observed during exercise in dogs. Clin Res 27: 380A

19. Schneider SH, Komanicky PM, Goodman MN (1979) Enhancement of exercise performance by dichloroacetate (DCA) in rats. Diabetes 28 (Suppl 2): 61

20. Cohen RD, Woods HF (1976) Clinical and biochemical aspects of lactic acidosis. Blackwell, London

21. Slein MW (1963) D-glucose. Determination with hexokinase and glucose-6-phosphate Dehydrogenase. In: Bergmeyer H-U (ed) Methods of enzymatic analysis. Academic Press, New York, 117-123

22. Westgard JO, Lahmeyer BL, Birnbaum ML (1972) Use of the Dupont "automated clinical analyzer" in direct determination of lactic acid in plasma solubilized with sodium fluoride. Clin Chem 18: 1334-1338

23. Chiasson JL, Liljenquist JE, Sinclair-Smith BC, Lacy WW (1975) Gluconeogenesis from alanine in normal postabsorptive man. Diabetes 24: 574-584

24. Lukas G, Vyas KH, Brindle SD, Le Sher AR, Wagner WE (1980) Biological disposition of sodium dichloroacetate in animals and humans after intravenous administration. J Pharm Sci 69: 419-421

25. Johnson RF, Schenker S, Roberts RK, Desmond PV, Wilkinson GR (1979) Plasma binding of benzodiazepines in man. J Pharm Sci 68: 1320-1322

26. Richens A (1979) Pharmacokinetics of phenytoin. Clin Pharmacokinet 4: 153-169

27. Levy G (1979) Pharmacokinetics of salicylate in man. Drug Metab Rev 9: 3-20

28. Katz R, Diener RM (1978) CGS 7937A (dichloroacetate): ninety-day oral toxicity studies in dogs. Ciba-Geigy, New York

29. Katz R, Diener RM (1978) CGS 7937A (dichloroacetate): ninety-day oral toxicity studies in rats. Ciba-Geigy, New York

30. Moore GW, Swift LL, Rabinowitz D, Crofford OB, Oates JA, Stacpoole PW (1979) Reduction of serum cholesterol in two patients with homozygous familial hypercholesterolemia by dichloroacetate. Atherosclerosis 33: 285-293

Received: October 24, 1979,

and in revised form: April 21, 1980

Dr. Peter W. Stacpoole

Division of Endocrinology

University of Florida

School of Medicine

Gainesville, FL 32610

USA 